Journal of Research in Interprofessional

Practice and

Education

Vol. 5.2

August 2015
Journal of Research in Interprofessional Practice and Education (JRIPE)

Vol. 5.2

(C) 2015

Corresponding author: Emma Ambrose Email: emmaclaireambrose @gmail.com

\section{Interprofessional Experiences at a Student-Run Clinic: Who Participates and What Do They Learn?}

\author{
Emma Ambrose, BSc; Dana Baker, BA; Inderveer Mahal, MD; \\ Aaron MicFlikier, MD; \& Maxine Holmqvist, PhD
}

\begin{abstract}
Background: Student-run clinics (SRCs) are student-driven, interprofessional community service-learning primary care initiatives in which students of different disciplines work collaboratively under the supervision of licensed healthcare professionals. Despite their increasing prominence and promise as vehicles for interprofessional education, little is known about the characteristics of students or mentors who participate in these initiatives.

Methods and Findings: A quality improvement review was conducted by members of the Winnipeg Interprofessional Student-Run Health (WISH) Clinic based on data collected in the first three years of clinic operation. Program records and anonymous feedback forms were examined for information regarding student and mentor characteristics (e.g., discipline, frequency of participation) and information regarding service provider satisfaction and recommendations. The clinic had low student retention, with the majority of students attending only one clinic shift. There was also limited student and mentor diversity, with medicine and nursing most highly represented. Qualitative information highlighted areas of strength and opportunities for improvement.

Conclusions: Recruitment and retention of students and mentors should be a priority for SRCs. Efforts devoted to increasing interprofessional diversity would likely benefit clients and allow for a more holistic approach to person-centred care. Keywords: Interprofessional education; Collaborative practice; Student-run clinics; Community service learning
\end{abstract}

\section{Introduction}

\section{Student-run clinics}

Student-run clinics (SRCs) were first introduced in the United States in the early 1960s in response to social concerns and economic barriers to health care [1]. The goal of SRCs is for students to provide healthcare and social services to underserved populations under the mentorship of licensed professionals. Although often operating similarly to primary care facilities, SRCs are unique in that they frequently provide public health education in addition to hands-on clinical experience for students and they seek to foster community service values in participating members. In addi- 
2

Interprofessional Experiences at a Student-Run Clinic

Ambrose, Baker, Mahal, MicFlikier, \& Holmqvist

Journal of Research in Interprofessional Practice and Education

Vol. 5.2

August 2015 tion to providing clinical care, students typically undertake the majority of operational and administrative duties (e.g., scheduling of volunteers and mentors, planning programs, preparing food) and play significant roles in providing primary healthcare and preventive services to patients/clients. Currently, it is estimated that there are 110 American SRCs operating from more than 49 medical schools [1]. The student-run free clinic movement has spread internationally, with pilot projects being established in countries such as South Africa, the United Kingdom, and Australia $[2,3]$.

The first Canadian student-run clinic, the Community Health Initiative by University Students (CHIUS), was established in Vancouver, British Columbia, in 2000. Since that time, there has been a growing interest in this particular model of healthcare delivery, with ten SRCs currently operating in Canada. Although SRCs were initially staffed solely by medical students and physicians, Canadian SRCs are increasingly adopting an interprofessional framework involving students and mentors from a variety of disciplines. These include but are not limited to medicine, clinical psychology, social work, physiotherapy, dental hygiene, nursing, occupational therapy, and physical therapy. These students collaboratively plan and work together to deliver healthcare and health promotion services under the supervision of professional mentors. Holmqvist et al. observe that this collaboration between learners both at the operational level and during clinical shifts at SRCs is a form of interprofessional education (IPE), as defined by the Centre for the Advancement of Interprofessional Education, "when two or more professions learn with, from and about each other to improve collaboration and the quality of care" [4]. In addition to helping students develop interprofessional competencies, this integration and involvement of multiple disciplines offers a unique chance to provide comprehensive care to underserved communities.

\section{WISH Clinic}

The Winnipeg Interprofessional Student-Run Health (WISH) Clinic is one of the largest student-directed interprofessional education (IPE) initiatives in Manitoba. The WISH Clinic is located in an inner-city neighbourhood where there is an imbalance between social and health requirements and resources. With support from the clinic facilitator, WISH student volunteers are responsible for accepting and orienting new students and mentors; fiscal management and funding acquisition; implementing health promotion events; triaging patients; and providing food, social supports, and community outreach.

The WISH Clinic is founded on a partnership between the University of Manitoba, Mount Carmel Clinic (the clinic site), the Winnipeg Regional Health Authority (WRHA), and the Point Douglas community. Although the structure of the WISH Clinic mirrors that of other Canadian student-run clinics, the legal arrangement between the University of Manitoba and Mount Carmel Clinic allows for liability coverage that is unique within a Canadian context, and WISH includes a broader range of disciplines than is typical in SRCs, nationally and internationally. The WISH Clinic started operations in March 2009 and offers a weekly half-day drop-in clinic on 
3

Interprofessional Experiences at a Student-Run Clinic

Ambrose, Baker, Mahal, MicFlikier, \& Holmqvist

Journal of Research in Interprofessional Practice and Education

Vol. 5.2

August 2015
Sundays between the hours of 1:30 p.m. and 4:30 p.m. Primary healthcare, social services (food, conversation, telephone, advocacy, child-care, computer resources), and health promotion services are provided to inner-city residents. Each shift is staffed and overseen by an attending physician and other health profession mentors from various disciplines. Before participating in WISH, both students and mentors receive an orientation that reviews the social determinants of health, clinical operational procedures, cultural appropriateness, and expectations of participants. Each WISH shift, students and mentors meet to discuss and review goals for that day and to review respective responsibilities. Students on the outreach team, which includes junior students and students not enrolled in a professional healthcare training program, greet patrons, prepare and serve food, and help facilitate health promotion programming. Health promotion activities include: interactive food preparation demonstrations (for kids and adults), health bingo, in which participants must answer questions relating to personal health, and other discipline-specific demonstrations. For example, students from occupational therapy put on a light circuit-training program for children that included stretches and exercises that could be done at home to improve physical health. They also showed the children's parents how to easily assess their child's gait development. Students on the healthcare team (senior students enrolled in a professional training program) provide walk-in clinical services collaboratively, alongside licensed healthcare mentors. Every shift is concluded with a debriefing session, which is led by the clinic facilitator or an experienced student volunteer.

WISH has been recognized by the WRHA as a primary care initiative that benefits the community [5]. WISH strives to be viewed as a sustainable centre of excellence that enables empowerment and continuity of care in partnership with the community in a stimulating reciprocal learning environment between patrons, students, and professional mentors. Patrons are community members who access WISH for social or outreach services; if they go on to access healthcare through the clinic, they become clients. Students are primarily volunteers who participate on their own time, although more recently, some programs have begun to offer course credit for participation at WISH. Mentors are licensed independent practitioners who assist students in enhancing personal and professional skills and ensure quality and consistency of care. In addition, as required by the legal arrangement between the university and the host clinic, all mentors are required to hold faculty appointments in order to participate at WISH. Although mentors do not receive specific training in facilitating in an interprofessional context, several of them participate in WISH because they have this as an interest (in fact, several were recruited through the provincial Interprofessional Education Initiative). In addition, the clinic facilitator and shift supervisor help guide the mentors in facilitating collaborative practice at the clinic. To encourage mentorship, WISH provides mentors with a modest honorarium for their time and services provided, with the exception of physician mentors. They are compensated at standard fee-for-service rates because WISH's legal agreement requires that an attending physician be present if clinical services are offered. One of the WISH physician mentors has a practice at WISH's host clinic during the week and provides follow-up for WISH Clinic clients as needed, thus providing continuity of care. 
4

Interprofessional Experiences at a Student-Run Clinic

Ambrose, Baker, Mahal, MicFlikier, \& Holmqvist
Journal of Research in Interprofessional Practice and Education

Vol. 5.2

August 2015
Mentorship also occurs at an administrative level. The WISH Clinic has both a steering committee and a student executive council, and together these committees are responsible for the management of the WISH Clinic. The steering committee consists of representation from students, university faculty, host clinic employees, and the WRHA. There are also three members on the steering committee who are exofficio: the department head and financial administrator for Community Health Sciences (the academic and administrative home of WISH) and the WISH clinic facilitator. The main purpose of the steering committee is to provide the student executive with guidance around issues such as strategic planning and fiscal management. The majority of day-to-day management of the clinic falls under the portfolio of the clinic facilitator and the student executive council, which has representation from all involved disciplines. Volunteers chair a variety of sub-committees, each of which supports WISH. One such committee is the quality improvement committee, whose mandate is to evaluate the WISH Clinic and provide recommendations to improve clinic operations.

\section{Quality improvement}

The quality improvement committee of WISH was created in the initial stages of clinic development and implementation. The committee identified various data collection tools to anonymously record information regarding patrons, clients, volunteers, and mentors. These data were gathered for the purposes of evaluation by WISH and were routinely collected during clinic shifts; however, until the current review, the data had never been systematically and comprehensively examined. In the fall of 2011 the quality improvement committee began an internal evaluation of WISH that utilized these data.

In this article, we focus on the distribution, characteristics, retention rates, and experiences of student volunteers and mentors. Given that WISH clearly identifies IPE as a core value, we focused on answering the following questions: 1) Which disciplines are represented at WISH, and how are they distributed among students and mentors? 2) How often do students participate at WISH (either as volunteers or for credit)? 3) How satisfied are students and mentors with their experiences at WISH, and what suggestions can be offered for improvement?

\section{Methods}

\section{Ethics approval}

The current study was performed initially as a quality assessment and improvement project for internal use by WISH. After consultation with the University of Manitoba Research Ethics Board, it was determined that research ethics board approval was not required as the data were being reviewed primarily for the purposes of program evaluation and the data in question were either anonymous or contained in an anonymized database. In addition, Mount Carmel Clinic's ethics committee reviewed and approved the study. Explicit permission was obtained from the WISH clinic student executive council and the WISH steering committee to analyze volunteer and mentor statistics and qualitative data. The WISH steering committee was consulted 
5

Interprofessional Experiences at a Student-Run Clinic

Ambrose, Baker, Mahal, MicFlikier, \& Holmqvist
Journal of Research in Interprofessional Practice and Education

Vol. 5.2

August 2015 throughout data collection and analysis to enhance interpretation. This committee provided their consent for the aggregate results to be publicly communicated.

\section{Measures and procedure}

\section{Quantitative information}

Students and mentors sign up for WISH clinic shifts in advance; attendance is then confirmed by the clinic facilitator or designate at the shift and recorded in a central database on a weekly basis. Information regarding the faculties of origin for volunteers and mentors, number of shifts attended, and patterns of participation were extracted from program records. Information regarding the student or mentor's discipline and whether they participated as a volunteer or for credit was determined from their WISH personnel file, created at the time that they registered with WISH. In rare cases where information was unclear or absent, clarification from the clinic facilitator or volunteer coordinator was obtained. Information gathered between March 2009 and January 2012 was entered into an anonymized Excel spreadsheet, which was then exported into SPSS, Version 19.

\section{Qualitative information}

To supplement these data, we reviewed responses to questionnaires that were completed voluntarily and anonymously by the students and mentors at the end of each shift. These questionnaires were developed locally by a faculty advisor specifically for the WISH Clinic to evaluate the overall experience of volunteers and mentors at the clinic, as well as to provide recommendations for improvement. The student questionnaires included the following questions: 1) What did you learn today? 2) What do you think you would like to know more about? 3) What experience(s) have you had that you feel you did not completely understand? 4) What additional help do you feel you need from the faculty or clinic staff? 5) Did you learn something today that you feel will help you in your future practice? If yes, please explain. The mentor questionnaires included the following questions: 1) Did the participants experience any difficulties throughout the afternoon? Please explain and describe how these were handled/managed. 2) How did the students communicate with each other, patients, and staff/faculty? 3) Did you observe anything in your group's interactions that were barriers to the team's ability to collaborate interprofessionally? 4) Were there any moments/experiences that were of particular importance or interest today? 5) What was the most positive moment today? 6) Please describe the interactions with the students and the patients and staff/faculty. 7) Please describe your overall thoughts and impressions of the day. In total, 250 student feedback forms and 43 mentor feedback forms were available for review, covering the time from 2009-2012. In addition to reviewing all of the available questionnaires, we consulted a thematic analysis of the data from 2009 that was conducted in early 2010 as a student research project.

\section{Analyses}

Means, standard deviations, and percentages were calculated using SPSS to provide descriptive information regarding clinic student volunteers and mentors. Student 
6

Interprofessional Experiences at a Student-Run Clinic

Ambrose, Baker, Mahal, MicFlikier, \& Holmqvist

Journal of Research in Interprofessional Practice and Education

Vol. 5.2

August 2015 and mentor questionnaires were transcribed by the first author, and feedback was examined for common themes by the first author and a second reviewer $(\mathrm{MH})$. For each question, a scoring rubric was developed and responses were coded independently; discrepancies were then resolved through discussion. For the student data, responses to questions 1 and 2 (relating to what students had learned and what they wished to know more about) were sorted into five broad categories: clinical/professional skills (learning how to do something related to future practice, like a physical exam or charting); interprofessional education and collaboration (learning about other disciplines, scopes of practice, or the importance of collaboration); community/social determinants of health (learning about local resources or about the challenges faced by community members); clinic operations (learning about WISH procedures); and ethics/personal development (where students indicated that they had learned something about themselves or their values). If multiple responses were given, each response was coded separately. In cases where more than one category was appropriate, the response was coded under both. For question 6, students were asked whether they had learned something they would use for future practice or not; responses were categorized as "yes," "no," or "no response." For mentors, questions 1, 2,3 , and 6 were reviewed. For question 1, relating to difficulties or barriers observed on shift, responses were coded as "difficulties observed, but managed well," "no difficulties observed," or "difficulties observed." For question 2, relating to student communication on shift, responses were coded as "positive" (i.e., mentor indicated that communication was good/strong) or "other." Question 3 related to barriers to collaboration observed on shift. Responses were coded as "no barriers observed" or "barriers observed." Finally, mentors were asked to give their overall impression of interactions between students, staff, and patrons or clients. These responses were coded as positive, negative, or neutral.

\section{Results}

\section{Student volunteer characteristics}

During the three-year assessment period, there were a total of 653 unique student volunteers registered at the WISH clinic, of whom 374 (57\%) were students volunteering at WISH as an extracurricular activity and 279 (43\%) were students who received credit for volunteering at WISH as part of a course requirement. The vast majority of students volunteering at WISH were enrolled in undergraduate programs. We observed a trend where students in non-professional undergraduate programs, such as human ecology or sciences, tended to volunteer in the later years of their program (years 3-4), whereas health profession students were more likely to volunteer in years 1 and 2 of their program and discontinue volunteership once they began clinical rotations.

Thirteen different academic units were represented by students volunteering at the WISH Clinic as an extracurricular activity: (arts [general], dentistry, education, extended education, human ecology, kinesiology, medicine, nursing, social work, occupational therapy, pharmacy, physical therapy, psychology, and respiratory therapy). Of these students, those from the faculties of medicine $(N=115 ; 30.7 \%)$ and 
JRIPE

7

Interprofessional Experiences at a Student-Run Clinic

Ambrose, Baker, Mahal, MicFlikier, \& Holmqvist

nursing $(N=70 ; 18.7 \%)$ made up the largest proportion (50\%) of volunteers (Table 1). The WISH Clinic was also used as a placement site for student in four courses in four different disciplines at the university (dental hygiene, health studies, occupational therapy, and pharmacy). Health studies students were required to volunteer once. Occupational therapy and dental hygiene students were required to volunteer twice; once as observers and subsequently as participants on the outreach team, offering educational displays to the community. Pharmacy students were required to complete a total of 40 volunteer hours in a community service-learning setting that focused on person-centred care. The 40 volunteer hours could be split among a number of sites, including WISH; however, the majority of their hours had to be completed at one location. Several pharmacy students volunteered for 7-10 shifts at the WISH Clinic. The distribution of "for-credit" students was quite similar between health studies (37\%), occupational therapy (33\%), and dental hygiene (28\%), while pharmacy accounted for only 3 percent of "for-credit" student volunteers (Table 1).

\section{Table 1. Distribution of academic units represented by student volunteers (extra-curricular and for-credit volunteers)}

\begin{tabular}{|l|c|c|}
\hline Faculty & Student volunteers & For-credit \\
\hline Arts & $2(0.53 \%)$ & - \\
\hline Dental hygiene & - & $77(27.60 \%)$ \\
\hline Dentistry & $3(0.08 \%)$ & - \\
\hline Education & $1(0.27 \%)$ & - \\
\hline Extended education & $2(0.53 \%)$ & - \\
\hline Human ecology & $52(13.90 \%)$ & $104(37.30 \%)$ \\
\hline Kinesiology & $1(0.26 \%)$ & - \\
\hline Medicine & $115(30.70 \%)$ & - \\
\hline Nursing & $70(18.70 \%)$ & - \\
\hline Occupational therapy & $39(10.40 \%)$ & $91(32.60 \%)$ \\
\hline Pharmacy & $24(6.42 \%)$ & $7(2.50 \%)$ \\
\hline Physiotherapy & $15(4.01 \%)$ & - \\
\hline Psychology & $15(4.01 \%)$ & - \\
\hline Respiratory therapy & $5(1.34 \%)$ & - \\
\hline Science & $16(4.28 \%)$ & - \\
\hline Social work & $11(2.94 \%)$ & - \\
\hline Unspecified & $3(0.80 \%)$ & 279 \\
\hline Total & 374 & \\
\hline
\end{tabular}

\section{Mentor characteristics}

Journal of Research in Interprofessional Practice and Education

Vol. 5.2

August 2015
During the three-year period there were a total of 42 mentors that attended the WISH Clinic, representing seven health disciplines: dental hygiene, medicine, nursing, occupational therapy, pharmacy, physical therapy, and psychology. Consistent with student volunteer trends, mentors from the Faculty of Nursing $(N=13 ; 31 \%)$ and from the Faculty of Medicine $(N=11 ; 26 \%)$ accounted for the majority of mentors, with the distribution across other disciplines as follows: pharmacy (17\%), den- 
8

Interprofessional Experiences at a Student-Run Clinic

Ambrose, Baker, Mahal, MicFlikier, \& Holmqvist tal hygiene (12\%), occupational therapy (10\%), psychology (5\%), and physiotherapy (2\%) (Table 2). Out of the 107 shifts that were evaluated for this study, 96 of these shifts had physicians present. All 11 physician mentors were specialized in family practice. None of the mentors from the Faculty of Nursing were nurse practitioners. Although there was keen interest to have nurse practitioners mentor at WISH, the limitations regarding liability and the requirements for all mentors to hold faculty appointments narrowed the pool of potential mentors.

\section{Table 2. Distribution of disciplines represented by licensed professionals mentoring at the WISH Clinic}

\begin{tabular}{|l|c|}
\hline Faculty & Number of mentors \\
\hline Dental hygiene & $5(11.90 \%)$ \\
\hline Medicine & $11(26.20 \%)$ \\
\hline Nursing & $13(40.00 \%)$ \\
\hline Occupational therapy & $4(9.52 \%)$ \\
\hline Pharmacy & $7(16.70 \%)$ \\
\hline Physiotherapy & $1(2.38 \%)$ \\
\hline Psychology & $1(2.38 \%)$ \\
\hline Total & $42(100 \%)$ \\
\hline
\end{tabular}

\section{Patterns of participation}

Student volunteer numbers were highly variable, ranging from as few as 6 students on a shift to as many as 57 students on a shift, with a median of 10.62 students per shift. Moreover, although medical and nursing students accounted for the majority of volunteers, over the 34 months there were several periods of time in which even these disciplines were represented in low numbers (see Figure 1).

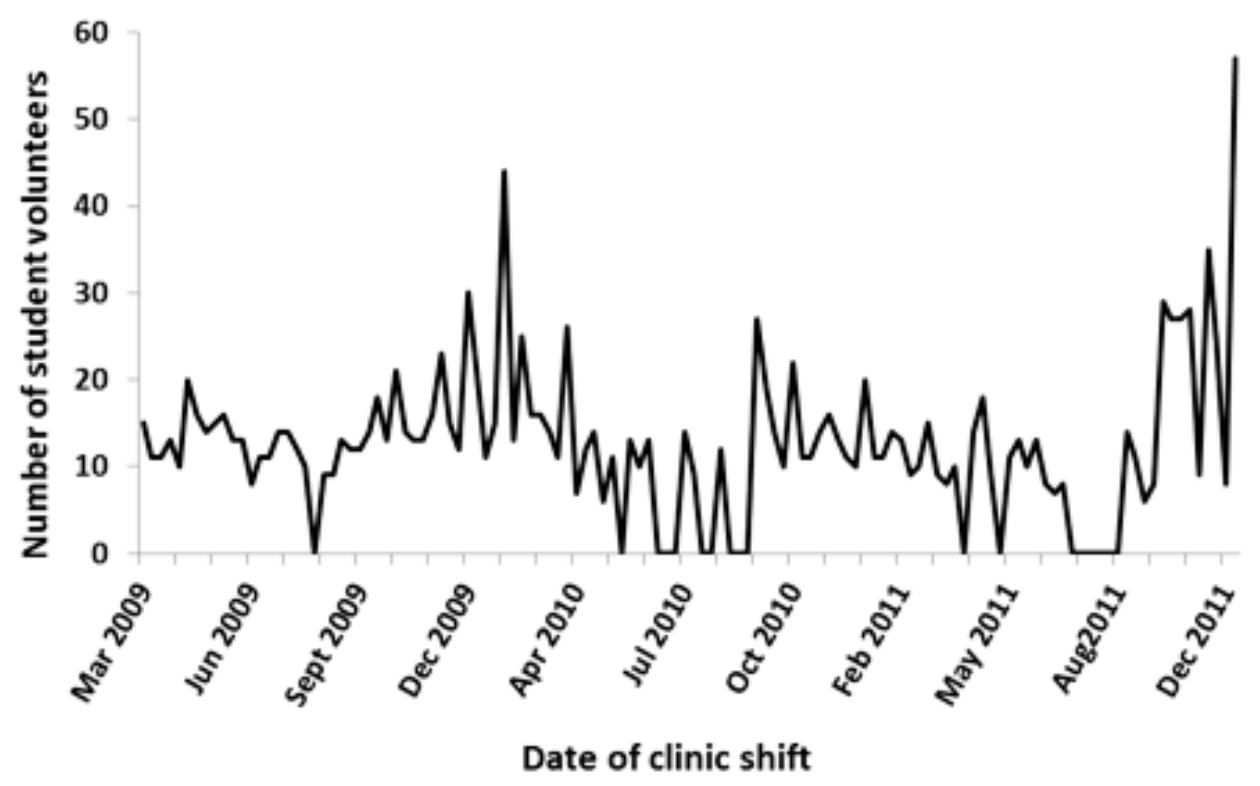

Figure 1. Number of volunteers per shift between 2009 and 2011 ( $N=653)$ 
JRIPE

9

Interprofessional Experiences at a Student-Run Clinic

Ambrose, Baker, Mahal, MicFlikier, \& Holmqvist

Several Canadian SRCs close for the summer, when the majority of students have a break in their program. This strategy is intended to prevent unplanned closures due to low volunteer numbers. Unplanned closures may result in unnecessary expenses related to paid staff, so this was a target of particular interest for sustainability. Instead of closing for the summer, the WISH Clinic closed on weekends that were linked to holidays (e.g., Thanksgiving). Data on clinic scheduling was available from March 2009 to January 2012, a timeframe in which the clinic was scheduled to be open for 122 shifts. During the first year, there were no unplanned closures. However, during 2010 and 2011 there were 15 unplanned closures, the majority of which occurred over the summer period (May 2010-August 2010, $N=6$; May 2011-August $2011, N=7)$. Of these 15 shifts, 13 were directly due to an insufficient number of volunteers to run the clinic.

\section{Frequency of participation}

The number of shifts per student ranged from zero shifts (i.e., received an orientation but did not attend WISH Clinic as a volunteer) to 38 shifts (Figure 2). The largest proportion of students volunteering at the WISH Clinic attended only one clinic shift after their orientation $(N=256,39 \%)$, whereas the second-largest group of students $(N=150,23 \%)$ participated in an orientation but did not attend a WISH Clinic shift. It should be noted that those students participating for credit received their orientation as part of a mass orientation session given to the entire class, and we were unable to differentiate these students in the data; this may have contributed to the high number of students that attended an orientation but did not volunteer.

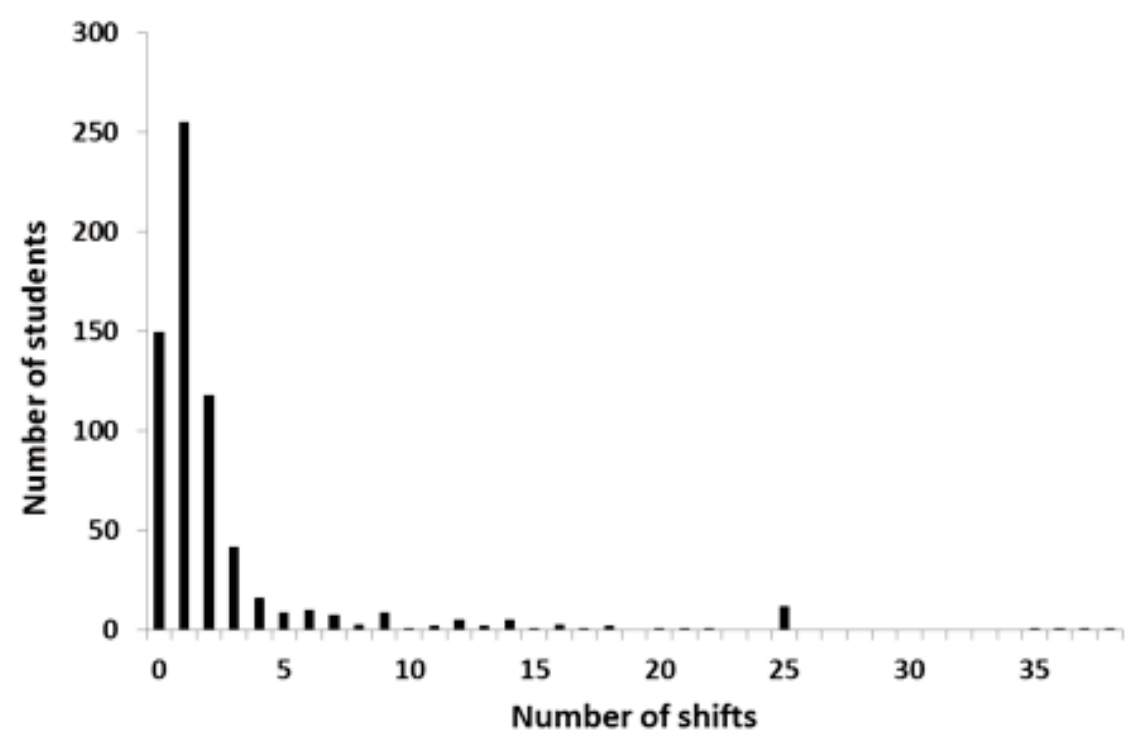

Journal of Research in Interprofessional Practice and Education

Vol. 5.2

August 2015

\section{Figure 2. Total number of shifts completed by all volunteers $(N=653)$}

On average, students attended a mean of 2.35 clinic shifts (median $=1$, mode $=1$ ) (Figure 2). We stratified the data between students volunteering as an extracurricular activity and those who participated for course credit to evaluate whether the sub- 
10

Interprofessional Experiences at a Student-Run Clinic

Ambrose, Baker, Mahal, MicFlikier, \& Holmqvist
Journal of Research in Interprofessional Practice and Education

Vol. 5.2

August 2015 stantial drop in student volunteers observed after the first or second clinic shift may in part be attributed to those students who were required to volunteer only once or twice to fulfill their course requirement Even among students who are "pure volunteers," the large drop in participation is still present; furthermore, only 71 (10.87\%) students volunteered for five or more shifts.

\section{Student and mentor feedback and recommendations}

Students described a wide range of experiences at WISH. Many of them appreciated being able to practice clinical skills early in their education. Several students $(42.4 \%)$ identified specific skills that they had learned, including clinical skills (e.g., taking a history, different charting formats, interviewing and counselling skills, learning how to complete lab requisitions and other forms) and $29.2 \%$ of respondents identified skills or learning related to clinic operational functioning (e.g., safe food handling procedures, data collection, budgeting, leadership, and task delegation/prioritization) (see Figure 3). Students also highlighted the various ways that they learned about the roles and skills of other disciplines, with $12.8 \%$ identifying that they learned through checkins and debriefing discussions, interactions with mentors and students of other professions during the shift, and through programming days. Many students indicated that their experiences at WISH were valuable to their clinical training, with $57.2 \%$ of students identifying specific things that they would use in future practice, and $7.6 \%$ noting that they had developed a personal skill or more in-depth insight from the perspective of a patient as a result of being at the clinic. Furthermore, they identified that their experiences interacting with and conversing with patrons in the social room made them aware of both the determinants of health and the similarities between clinic patrons and themselves (with $20.4 \%$ specifically reporting that they had learned about the community or the social determinants of health).

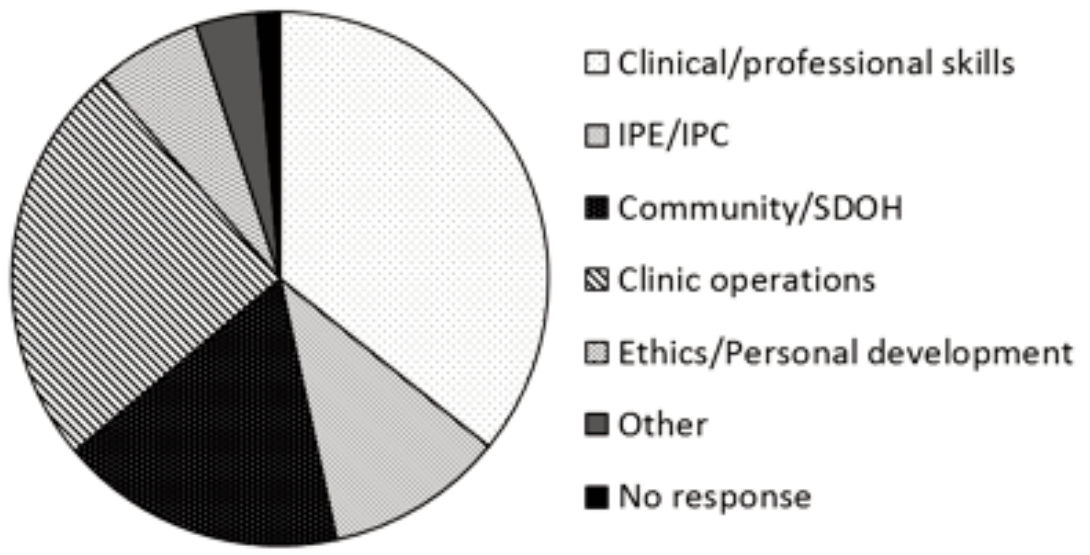

Figure 3. Categories of student responses to the question "What did you learn today?"

The most common challenge identified by students was that they felt unprepared for the clinic shift and were not aware of their exact role. This was particularly notable among new volunteers (i.e., individuals who identified on the form that this 
11

Interprofessional Experiences at a Student-Run Clinic

Ambrose, Baker, Mahal, MicFlikier, \& Holmqvist

Journal of Research in Interprofessional Practice and Education

Vol. 5.2

August 2015 was their first time at the clinic). When asked the question, "What do you think you would like to know more about?" $22.8 \%$ of students indicated they wanted to build further on their clinical or patient-professional interaction skills. Both clinical and outreach students felt that they wanted to improve their communication/rapportbuilding skills, with $8.0 \%$ of students specifically identifying a need to learn how to do this better. In addition, $10.0 \%$ of students wanted to know more about interprofessional education or collaboration. Several students also indicated a desire to learn more about the community (10.0\%) and resources available to the community (16.0\%), while $16.8 \%$ reported wanting to know more about WISH and WISH's clinical operations. A total of $22.4 \%$ of students reported "nothing" or did not provide a response, while $2.0 \%$ reported "everything."

Some students expressed disappointment with a lack of consistency between shifts. In particular, students enrolled in healthcare programs mentioned that they were discouraged when they were unable to see a patient in the primary care clinic at WISH. Students who were part of the outreach team indicated that at times they encountered situations in the community room that were unfamiliar to them, causing them to feel unsure or uncomfortable. Specific, reoccurring examples include not knowing how to approach patrons; not knowing how to respond when certain topics were raised, and; being unsure how to manage patrons who were agitated, emotionally escalated, or possibly intoxicated.

Similar to the student volunteers, feedback from mentors was primarily positive, with $76.7 \%$ giving a positive overall response to the day and $0 \%$ providing negative responses. Many mentors specifically noted that they were pleased with student involvement and maturity, with $91.0 \%$ indicating that they felt students communicated well; of those, $41.0 \%$ used either "respectful" or "effective" as descriptors. A total of $70.0 \%$ of mentors indicated that they did not observe any difficulties on shift, while $7.0 \%$ noted that there were some difficulties but that these were handled well. Similarly, $72.1 \%$ of mentors did not describe any specific barriers to collaboration on shift. In addition, mentors commonly indicated that they felt personal satisfaction with their own interaction with clinic patrons and that they had learned a lot from their experiences.

Common concerns or barriers raised by mentors were in relation to the patient flow in the primary care clinic. Some mentors felt that the client visit took too long, which led to client discomfort and dissatisfaction, whereas other mentors felt that they did not have enough time to thoroughly debrief with the students during the client visit. Mentors also expressed concern about supervising students from other faculties and had questions about legal and professional responsibilities and sign off in terms of cross competencies. Of note, when asked if they had any major concerns, all mentors who responded stated that they did not have any major concerns to express.

Lastly, recommendations for improvement from students and mentors were reviewed. Students frequently mentioned that they saw a great need for counselling services for clinic patients and described wanting more activities in the community room to help break down barriers and build communication with and between community members. They also suggested that a more robust orientation that included 
12

Interprofessional Experiences at a Student-Run Clinic

Ambrose, Baker, Mahal, MicFlikier, \& Holmqvist

Journal of Research in Interprofessional Practice and Education

Vol. 5.2

August 2015 safety training regarding concerns that arise in the community room (e.g., strategies for managing intoxicated or extremely ill patrons) would be helpful. Students wanted to see more disciplines represented by mentors to allow for a greater scope of service provision. Several healthcare students were unable to practice their skills due to a lack of mentorship available at the clinics they attended (for example, social work students were unable to provide counselling without a social work mentor present). In more recent years, a number of students specifically identified wanting WISH to improve their framework to better involve students from occupational therapy and physical therapy.

Mentors primarily commented on improvements that could be made in order to help them feel more prepared for clinic, such as improving the mentor manual and providing them with better access to clinic policies and procedures when needed. Mentors also mentioned that being more familiar with the site and having more consistent volunteer numbers would improve their facilitation of service delivery. Finally, both mentors and students identified that it would be helpful to know more about other services available both at the host clinic and within the community. This knowledge would allow WISH Clinic volunteers to refer patrons to, or connect patrons with, other agencies in the community when WISH was unable to meet all of their needs (e.g. housing, addictions programs, and ongoing counselling).

\section{Discussion}

SRCs are an increasingly important part of the healthcare landscape in Canada. While there has been some documentation of the kinds of services offered through these clinics [6], to our knowledge, we are the first clinic to report detailed evaluation data regarding the providers of these services. In addition to describing our "workforce," we suggest that several aspects of the data presented here may be of value for other SRCs to consider, as we anticipate the themes identified and potential solutions are not unique to WISH.

Like other SRCs, WISH is a student-driven and -run initiative; as such, student participation is a key target for the WISH Clinic. Despite positive feedback on the student questionnaires, our data demonstrate that a frequent logistical challenge for WISH is maintaining a sufficient number of student participants, especially during the summer months. As the struggle to maintain consistent volunteer numbers over time is a perennial one for many SRCs, these data sets suggest some ways that these numbers might be improved. Several Canadian SRCs close their doors over the summer months (May-August) to cope with the lack of volunteers available over the university break; however, this may have a negative impact on those community members who rely heavily on the services and resources provided by those clinics. WISH now manages this reduction of volunteers over the summer months by reducing the number of clinics each month from four to two in order to maximize limited resources while minimizing disruption in service.

Another area of concern is the significant rate of attrition following the orientation session and after the first time volunteering. Given the considerable dedication, effort, and thought required to orient students to the clinic, we suggested that SRCs 
Interprofessional Experiences at a Student-Run Clinic

Ambrose, Baker, Mahal, MicFlikier, \& Holmqvist

Journal of Research in Interprofessional Practice and Education

Vol. 5.2

August 2015 experiencing this problem may want to consider instituting measures that aim to address this directly. These might include, but would not be limited to, gathering additional data about the orientation itself to determine how it might be improved, requiring that students sign up for a minimum number of shifts either at the orientation or prior to being oriented, and following up individually with volunteers following their first or second shift in order to get feedback about their experiences and to encourage further participation. It may also be helpful to consider ways to encourage involved students to remain involved as they progress through their programs. When students in health professional programs were asked why they stopped volunteering, common responses were that the time commitment from their program was too great to continue volunteering at WISH throughout their training; students also indicated that as they began to get more clinical experience in their program they were not gaining as much by volunteering at WISH.

One strategy that is not likely to be helpful would be increasing the number of students participating for class credit. While it is reasonable to hypothesize that exposing students to a clinic shift at WISH could lead to these students becoming regular volunteers, there was no evidence to support this: the vast majority of those who participated at WISH for credit did so only for the required number of shifts. In contrast to this, one group of interest is those students who volunteered for 10 or more shifts. While this was neither typical nor representative of their peers, following up with these students may identify ways to increase motivation or involvement across the group as a whole. Finally, recruitment of student volunteers with strong leadership skills could potentially be an asset. Appointing select standout volunteers as leaders from various faculties may encourage more students to volunteer and may also encourage those who are already volunteering to continue to do so, rather than only volunteering once or twice. Our data indicate that individuals who are involved with leadership activities, such as membership on the executive council, tend to volunteer more frequently in the clinic, while previous studies have demonstrated that students who took on coordinator or leadership roles had a better understanding of the roles of other health professions in the clinical setting [7]. We have observed that individuals who had leadership roles at WISH also participated actively in national and international organizations involving SRCs and organizations dedicated to IPE (e.g., Canadian International Health Collaborative, All Together Better Health). Although no formal leadership training was provided through WISH, the co-chairs of the clinic as well as other clinic leaders were guided by members of the steering committee when undertaking specific tasks (e.g., running shifts, managing budgets, strategic planning). These interactions served to empower students and supported growth of leadership skills, especially in the context of healthcare administration. We suggest that SRCs should look to actively recruit students and mentors who could serve as excellent advocates and networkers for their clinics and consider including both formal and informal opportunities for leadership development.

Finally, although high drop-out rates among first-time volunteers have been seen in other student-run clinics, there are SRCs that maintain high rates of student participation, in conjunction with a high percentage of these volunteers continuing their 
14

Interprofessional Experiences at a Student-Run Clinic

Ambrose, Baker, Mahal, MicFlikier, \& Holmqvist

Journal of Research in Interprofessional Practice and Education

Vol. 5.2

August 2015 volunteership the following year and also taking on leadership roles [7]. We suggest that it is of value for SRCs to study the practices of clinics that have excellent retention rates in order to determine what factors support ongoing participation.

Volunteer involvement and satisfaction is, to some extent, contingent on the involvement and satisfaction of mentors who help to guide participation and clinical experiences. While the majority of students were satisfied with their experience and expressed an interest in learning about the educational goals of other health profession students, a select cohort expressed disappointment in the lack of patient interaction. This is mirrored in a study by Hadjistavropoulos, who found that students participating in a one-day interprofessional workshop highlighted their preference to learn from client presentations [8]. Concerns identified by mentors relating to client flow can likely be attributed at least in part to variability in the numbers of patrons seeking clinical services on different shifts and the complexity of presenting concerns. In addition, if the majority of students at the WISH Clinic volunteered only once or twice, mentors would have to take more time guiding students through the process. It is important to note that the majority of mentors that responded to the feedback questionnaires described positive and enriching experiences.

Not only are mentors critical in terms of assuring quality of clinical care, both mentors and students identified the interprofessional aspect of WISH as a unique strength, suggesting that WISH and similar clinics may benefit from enlisting mentors from a variety of health and social professions. At WISH, student and mentor involvement remains heavily weighted toward medicine and nursing. In part, this can be explained by the fact that these professions tend to have large "pools" of potential volunteers to draw from (e.g., medicine class sizes are approximately 110 students per year, as compared to 50 for physical therapy and 5 for clinical psychology). The greater participation by medicine may also be influenced by the different way that physician mentors are compensated for their time, and the fact that WISH is supported by a local memorial program that supports health equity, an initiative of the College of Medicine. Finally, we suspect that medicine and nursing can easily conceptualize their roles as part of the healthcare team, while the roles of other disciplines may not be as immediately apparent to all. A less diverse workforce limits the kinds of clinical services that can be offered to patrons, dilutes the richness of the interprofessional experience, and limits the scope of programming opportunities that may be developed. This is unfortunate because opportunities for person and family-centred care and health promotion at SRCs are vast and we suspect that more structured outreach programming may help students to more fully appreciate the role of the outreach team.

In addition to specifically targeting recruitment of those disciplines with more limited participation as suggested above, we suggest that working with designated faculty mentors to further clarify the potential roles of different disciplines and identify barriers to participation may be helpful. It is likely that a coordinated approach is required here; mentors appear to appreciate having students of their own discipline to mentor, while volunteers frequently cannot practice to their full scope without a discipline-specific mentor. We suggest that when targeting a particular 
Interprofessional Experiences at a Student-Run Clinic

Ambrose, Baker, Mahal, MicFlikier, \& Holmqvist

Journal of Research in Interprofessional Practice and Education

Vol. 5.2

August 2015 discipline for recruitment, it may be helpful simultaneously to identify student and mentor champions. Increasing the available pool of mentors may help address challenges to sustainability by ensuring that there are enough mentors to run a clinic.

There are a number of limitations to this study, many of which have been identified. At the time of writing, student and mentor data were available for the years 2009-2012; these numbers will not reflect the effects of recent efforts to improve recruitment and retention of volunteers. Qualitative data were based on feedback forms that were voluntary and anonymous; thus, responses are only available from a self-selected sub-set of the whole population of students and mentors, who may or may not be representative. Furthermore, feedback forms were distributed to students and mentors on nearly every shift; therefore, it is possible that there are multiple responses from the same individuals. We also noted that in recent years, feedback forms were not distributed as frequently or as consistently as in earlier years, and there was a large amount of missing data or data that was difficult to interpret on the forms that were completed. Finally, not all of the mentor and student feedback forms were available for us to review; however, we note that our findings are highly consistent with a previous analysis that was completed based on the first year of the clinic (2009-2010).

As a result of this study, WISH has instituted a number of new initiatives. These include enhanced strategies to improve communication with current and potential volunteers (using a secure online learning platform to share and store information related to administrative and clinical roles, processes, and programming) and with local agencies and the host community through an improved external website. WISH has also developed mutually beneficial partnerships with several agencies in the community. These agencies provide training to WISH students and also expand on the services provided at the WISH Clinic during health promotion events, and WISH provides a platform for these agencies to reach out to the community. To improve volunteer retention, WISH is piloting a new system for recruiting volunteers that involves more intensive screening prior to registering as a volunteer, and personalized follow up with volunteers after their first shift. Finally, with the assistance of the QI committee, WISH is developing a research and evaluation strategy that will help to ensure the ongoing commitment to serve the community and healthcare students is met.

SRCs can be powerful learning environments and adjuncts to the usual avenues of care. Research suggests that students who complete part of their training in underserved areas are more likely to practice in these communities after graduation [9], and SRCs specifically may help to offset the typical decline in interprofessional attitudes seen as a result of professional socialization [10]. Indeed, a recent report on Canadian clinics suggests that these may be ideal sites for inculcating values related to IPE [6]. Despite this potential, the challenges faced by SRCs are great: in an age of decreased spending for healthcare and education, we suggest that SRCs need to become actively engaged in continuous monitoring and quality improvement. This process has begun in some American clinics, and we highly recommend it be extended into Canadian SRCs [11]. A commitment to data and quality improvement will strongly help facilitate SRCs meet their goals of providing a high quality holistic 
JRIPE

Interprofessional Experiences at a Student-Run Clinic

Ambrose, Baker, Mahal, MicFlikier, \& Holmqvist
Journal of Research in Interprofessional Practice and Education

healthcare to their communities while also supporting the acquisition of clinical skills and patient communication for future healthcare providers.

\author{
Abbreviations \\ IPE Interprofessional eduction \\ SRC Student-Run Clinic \\ WISH Clinic Winnipeg Interprofessional Student-Run Health Clinic
}

\section{References}

1. Simpson, S.A., \& Long J.A. (2007). Medical student-run health clinics: Important contributors to patient care and medical education. Journal of General Internal Medicine, 22, 352-356.

2. Favara, D.M., \& Mendelsohn, S.C. (2012). The students' health and welfare centres organisation (SHAWCO) of the University of Cape Town: A review of the past 69 years. South African Medical Journal, 102, 400-402. URL: http://www.samj.org.za/index.php/samj/article/view /5446/4207 [September 1, 2014].

3. Kent, F., \& Keating J. (2013). Patient outcomes from a student-led interprofessional clinic in primary care. Journal of Interprofessional Care, 27, 336-338.

4. Holmqvist, H., Courtney, C., Meili, R., \& Dick, A. (2012). Student-run clinics: Opportunities for interprofessional education and increasing social accountability. Journal of Research in Interprofessional Practice and Education, 2, 264-277. URL: http://www.jripe.org/index.php/journal/article/view/80 [September 1, 2014].

5. Building a Primary Care System: Community Perspectives on Primary Care Home and Network. (2011). Community Health Advisory Councils Report. Winnipeg, MB. Winnipeg Regional Health Authority. URL: http://www.WRHA.mb.ca/about/engagement/lhig/files/CHAC_Report _Jan11.pdf [September 1, 2014].

6. Haggerty, D., \& Dalcin, D. (2014). Student-run clinics in Canada: An innovative method of delivering interprofessional education. Journal of Interprofessional Care, 28, 570-572.

7. Sheu, L., O’Brien, B., O’Sullivan, P., \& Wong, A. (2013). Systems-based practice learning opportunities in student-run clinics: A qualitative analysis of student experiences. Acadmic Medicine, 88, 831-836.

8. Hadjistavropoulos, H.D., Juckes, K., Dirkse, D., Cuddington, C., Walker, K., Bruno, P., White, G., Ruda, L., \& Pitzel Bazylewski, M. (2015). Student evaluations of an interprofessional education experience in pain management. Journal of Interprofessional Care, 29(1), 73-75. URL: http://informahealthcare.com/doi/abs/10.3109/13561820.2014.917613 [September 1, 2014].

9. Tavernier, L.A., Connor, P.D., Gates, D., \& Wan, J.Y. (2003). Does exposure to medically underserved areas during training influence eventual choice of practice location? Medical Education, 37, 299-304.

10. Sick, B., Sheldon, L., Ajer, K., Wang, Q., \& Zhang, L. (2014). The student-run free clinic: An ideal site to teach interprofessional education? Journal of Interprofessional Care, 5, 413-418.

11. Butala, N.M., Murk, W., Horwitz, L.I., Graber, L.K., Bridger, L., \& Ellis, P. (2012). What is the quality of preventative care provided in a student-run free clinic? Journal of Health Care for the Poor and Underserved, 23, 414-424.
Journal of Research in Interprofessional Practice and Education

Vol. 5.2

August 2015 